\title{
EL QUEBRANTAMIENTO DEL ESTADO DE DERECHO POR LOS TITULARES DE LA ADMINISTRACIÓN PÚBLICA HONDUREÑA Y SU EFECTO DIRECTO EN LA TRANSPARENCIA, LA CORRUPCIÓN Y LA IMPUNIDAD
}

\author{
Oscar Alfredo Fernández Fernández ${ }^{1}$ \\ RESUMEN: \\ DOI: https://doi.org/10.5377//rd.v42i1.12927
}

El interés de la presente ponencia es en un primer momento ilustrar la evolución histórica y establecer que se entiende en la actualidad por un Estado de Derecho, el cual diremos que consiste básicamente en: La existencia de Imperio de la Ley, La Distribución del Poder Estatal, La Legalidad de la Administración y La responsabilidad de las autoridades y Respeto y garantía de los Derechos Humanos a través del ordenamiento jurídico.

Posteriormente nos enfocaremos en plantear lo relativo al Estado de Derecho en Honduras y el papel que han desempeñado los Titulares de la Administración Pública Hondureña entorno a este, exponiendo lo que establece tanto la Constitución de la República como la Ley General de la Administración Pública, en donde, de acorde a la prelación anterior, por un lado, se nos dice que Honduras es un Estado de Derecho y por el otro que la Administración Pública tiene por objeto fortalecer ese Estado de Derecho.

Seguido a lo anterior se evidenciará como en Honduras a través de los Titulares de la Administración Pública se han violentado las bases de todo Estado de Derecho por medio de: a) el irrespeto del principio de división de poderes a través de la concentración de poder en el Poder Ejecutivo y la subordinación a esté de los demás Poderes del Estado por medio del Consejo Nacional De Seguridad y Defensa, b) El Irrespeto del Derecho Humano al Acceso a la Información Pública y c) El irrespeto al Imperio de la Ley por la violación directa a la Constitución de la República.

Llegando a la conclusión de que el actuar de los Titulares de la Administración Pública ha provocado el quebrantamiento del Estado de Derecho en el territorio nacional, afectando directamente la transparencia en el actuar administrativo, fomentando la violación de Derechos Humanos, la Corrupción y la Impunidad, colocándonos en el cuarto lugar en relación a los países más corruptos de América Latina y el número uno respecto a los índices de impunidad en dicha región.

Y por último estableceremos el actuar equivocado por parte de los Titulares de la Administración Pública ante la ausencia del Estado de Derecho en el manejo de la Emergencia Nacional generada por el Covid-19 en donde ha imperado la corrupción llevándose de encuentro vidas hondureñas y agudizando la pobreza en el país.

PALABRAS CLAVE: Estado de Derecho, Administración Pública, Poder Ejecutivo, El Presidente de la Republica, El Derecho Humano de Acceso a la Información, División de Poderes, Imperio de la Ley, Transparencia, Corrupción, Impunidad.

Fecha de recepción: 6/2/2021

Fecha de aprobación: 18/11/2021

\footnotetext{
${ }^{1}$ Abogado Privado, egresado de la Carrera de Derecho por la Universidad Nacional Autónoma de Honduras, Correo Electrónico: oafernandez@unah.hn
} 


\title{
THE VIOLATION OF THE RULE OF LAW BY THE HOLDERS OF THE HONDURAN PUBLIC ADMINISTRATION AND ITS DIRECT EFFECT ON TRANSPARENCY, CORRUPTION AND IMPUNITY
}

\author{
Oscar Alfredo Fernández Fernández² \\ DOI: https://doi.org/10.5377//rd.v42i1.12927
}

\begin{abstract}
The interest of this presentation is at first to illustrate the historical evolution and establish what is currently understood by a State of Law, which we will say that it consists basically of: The existence of the Rule of Law, The Distribution of State Power, The Legality of the Administration and The responsibility of the authorities and Respect and guarantee of Human Rights through the legal system.

Subsequently, we will focus on raising issues related to the Rule of Law in Honduras and the role that the Honduran Public Administration Holders have played around it, exposing what is established by both the Constitution of the Republic and the General Law of Public Administration, in where, according to the previous priority, on the one hand, we are told that Honduras is a State of Law and, on the other, that the Public Administration aims to strengthen that State of Law.
\end{abstract}

Following the above, we will evidence how in Honduras, through the Holders of the Public Administration, the foundations of all rule of law have been violated by means of: a) disrespect for the principle of division of powers through the concentration of power in the Executive Power and the subordination to it of the other Powers of the State through the National Security and Defense Council, b) Disrespect for the Human Right to Access to Public Information and c) Disrespect for the Rule of Law due to direct violation to the Constitution of the Republic.

Reaching the conclusion that the actions of the Public Administration Holders have caused the violation of the Rule of Law in the national territory, directly affecting the transparency of administrative actions, promoting the violation of Human Rights, Corruption and Impunity, placing us in fourth place in relation to the most corrupt countries in Latin America and number one in terms of impunity rates in that region.

And finally, we will establish the wrong action on the part of the Public Administration Holders in the absence of the Rule of Law in the management of the National Emergency generated by Covid-19, where corruption has prevailed, ending hondurans lifes and exacerbating the poverty in the country.

KEY WORDS: Rule of Law, Public Administration, Executive Power, The President of the Republic, The Human Right of Access to Information, Division of Powers, Rule of Law, Transparency, Corruption, Impunity.

Date received: $2 / 6 / 2021$

Approval Date: 11/18/2021

${ }^{2}$ Private Lawyer, graduated from the Law School of the National Autonomous University of Honduras, Email: oafernandez@unah.hn

50-|Revista de Derecho. Vol. 12, No. 1, Año 2021

ISSN: 2509-5296 (Impreso) 


\section{INTRODUCCIÓN}

La concentración de Poder en el Poder Ejecutivo es una tendencia generalizada en América Latina, causando esto prácticas que no son propias de la democracia y afectando al Estado de Derecho, el cual ha sido desarrollado desde hace muchos años gracias a las tendencias liberales que luchaban en contra los gobiernos Absolutistas y Autoritarios. Convirtiéndose así EL Estado de Derecho en la Institucionalización Jurídica de la Democracia, gracias a garantizar que en todo país se cumpla: el Imperio de la Ley, La División de Poderes, El control y fiscalización de los Poderes Públicos y el Respeto y Garantía de los Derechos Humanos.

Es por ello que se considera de suma importancia identificar todas aquellas practicas por parte de los gobernantes que pongan en peligro o quebranten por completo el Estado de Derecho en la búsqueda de llenar su pecunio personal con el erario público o la obtención del poder absoluto.

Debido a todo lo antes expresado se ha tomado a bien desarrollar el presente trabajo, el cual se centra en El Estado de Honduras, a través de este expondremos como los Titulares de la Administración Pública Hondureña han violentado las bases del Estado de Derecho hasta llegar al quebrantamiento por completo de este, obteniendo como resultado la Violación de Derechos Humanos, la no Rendición de Cuentas en la Administración Pública, la Corrupción y la Impunidad en el país. Esperando que el presente trabajo pueda ser usado como referente en el contexto Latinoamericano para identificar y erradicar todas aquellas prácticas contrarias al Estado de Derecho y se entienda a plenitud el papel que desempeñan los Titulares de la Administración Pública en la correcta aplicación del Estado de Derecho.

Nadie garantiza que en el futuro no llegarán más pandemias que generen estados de emergencia y como se expone a continuación la respuesta Administrativa Hondureña ante la ausencia del Estado de Derecho es un caos, llevándose de encuentro vidas humanas y dejando a la economía en ruinas, es por esto la necesidad de fortalecer el Estado de Derecho en la región

\section{METODOLOGÍA}

En el desarrollo del presente trabajo investigativo se empleó un enfoque cualitativo ya que este reúne las características de ser analítico, descriptivo y explicativo; partiendo con un método Formal-Jurídico en el cual se busca contextualizar como se concibe el Estado de Derecho y como va evolucionando hasta llegar a la definición actual; así como también se busca tener una idea clara en base al estudio del ordenamiento jurídico hondureño, de que es y cómo funciona La Administración Pública.

Decimos que es analítico porque se ha analizado el Ordenamiento Jurídico Nacional e Internacional para poder entender el rol que juegan los Titulares de la administración Pública ante el Estado de Derecho. Así mismo es descriptivo y explicativo porque se describe y explica la realidad nacional ante el quebrantamiento del Estado de Derecho por los Titulares de la Administración Pública.

\section{DESARROLLO}

3.1. El Estado de Derecho

ISSN: 2521-5159 (En Límea)

Revista de Derecho. Vol. 42, No. 1, Año $2021 \mid-51$ 
El Estado de Derecho tiene sus raíces en la antigüedad clásica, en la Política de Aristóteles, y en las obras de Cicerón. Durante el siglo XIII, Tomás de Aquino, argumentó que el imperio de la ley representa el orden natural de Dios tal como se determina a través de la inspiración divina y la razón humana. En el siglo XVII, el jurista inglés Sir Edward Coke, afirmó que "el rey no debe estar bajo ningún hombre, sino bajo Dios y la ley". Con respecto al poder legislativo en Inglaterra, Coke dijo que "cuando un acto del Parlamento es contrario al derecho común y a la razón, o repugnante, o imposible de llevar a cabo, el derecho común lo controlará, y juzgará dicho acto como nulo". En Estados Unidos, de América Alexander Hamilton aplicó el imperio de la ley al poder judicial cuando argumentó en The Federalist, no. 78, que los jueces no tienen ni fuerza ni voluntad, sino simplemente juicio. ${ }^{3}$

El principio fue elaborado y denominado definitivamente como "Estado de Derecho" por el destacado teórico constitucional inglés del siglo XIX, Albert Venn Dicey, (1835-1922). En su influyente obra Introducción al Estudio del Derecho de la Constitución (1885), Dicey, clasificó el Estado de Derecho con la soberanía parlamentaria y las convenciones constitucionales como uno de los tres elementos fundamentales de la Constitución Británica no escrita. Le dio tres significados al término Estado de Derecho que se mencionan a continuación: un requisito de que el gobierno actúe contra el ciudadano solo de conformidad con el derecho común aplicado en los tribunales ordinarios y no de manera arbitraria o en el ejercicio de una amplia autoridad discrecional; un requisito de que el

3 INTERNACIONAL, "Plataforma Digital de Derecho, Ciencias Sociales y Humanidades”, Historia del Estado de Derecho, 21 de febrero del 2020, Disponible en línea: https:// leyderecho.org/historia-del-estado-de-derecho/, Acceso en 16 do octubre del 2020. gobierno y todos los ciudadanos sean iguales ante la ley y estén igualmente sujetos a los tribunales ordinarios; y una formulación que refleje el hecho de que los derechos constitucionales no se basan en principios abstractos, sino en el derecho común de la tierra aplicado en los tribunales. ${ }^{4}$

En la actualidad la idea del Estado de Derecho está aceptado casi unánimemente por la mayoría de países de Latinoamérica. Ha sido un ideal en extremo poderoso para los que luchan contra el autoritarismo y el totalitarismo en las últimas décadas y es considerado uno de los pilares principales de un régimen democrático. Los defensores de los Derechos Humanos ven en el Estado de derecho una herramienta indispensable para evitar la discriminación y el uso arbitrario de la fuerza.

Seguido a lo anterior podemos decir que el Estado de Derecho moderno consiste en estar sometido a un ordenamiento jurídico, el cual constituye la expresión auténtica de la idea de Derecho vigente en la sociedad, siendo sus bases las siguientes:

- Imperio de la Ley: las normas deben ser expresión de la voluntad popular y deben someterse a ella tanto gobernantes como gobernados.

- Distribución del poder estatal en diferentes órganos: de esta manera el poder del Estado no se concentra en una sola institución, sino que se distribuye permitiendo mayor eficiencia y los debidos controles, evitando arbitrariedades y abuso de poder.

4 INTERNACIONAL, "Plataforma Digital de Derecho, Ciencias Sociales y Humanidades", Historia del Estado de Derecho, 21 de febrero del 2020, Disponible en línea: https://leyderecho.org/historia-del-estado-de-derecho/, Acceso en 16 do octubre del 2020. 
- Legalidad de la administración y responsabilidad de las autoridades; sea penal, civil, administrativa y política.

- Respeto y garantía de los Derechos Humanos a través del ordenamiento jurídico el que también contempla los mecanismos o recursos que se pueden interponer en caso de atropello o violación. Esta es una de las notas definitorias de Estado de Derecho, pues incluso en los regímenes totalitarios han existido normas, tribunales y leyes; pero estos se caracterizaban por la vulneración de los derechos esenciales de las personas. ${ }^{5}$

\subsection{La Administración Pública hondureña}

Es importante mencionar que la Constitución de la Republica en su artículo 1 establece que Honduras es un Estado de Derecho, articulo el cual plantea literalmente lo siguiente: Honduras es un Estado de Derecho, soberano, constituido como república libre, democrática e independiente para asegurar a sus habitantes el goce de la justicia, la libertad, la cultura y el bienestar económico y social. $^{6}$

Enrelacióndirectaaloanteriormenteexpresado en Ley General de la Administración Pública en su artículo 5 expresa que la Administración Pública tiene por objeto "El fortalecimiento del Estado de Derecho para asegurar una sociedad política, económica y socialmente justa con arreglo a los principios de descentralización, eficacia, eficiencia, probidad, solidaridad, subsidiaridad,

5 Biblioteca del Congreso Nacional de Chile, Guía de Formación Cívica - Estado, Disponible en Línea: https://www.bcn. $\mathrm{cl} /$ formacioncivica/detalle_guia? $\mathrm{h}=10221.3 / 45680$, Acceso en 16 de octubre del 2020.

6 PODER LEGISLATIVO, Constitución de la Republica de Honduras, Tegucigalpa M.D.C, Diario Oficial la Gaceta, 20 de enero de 1982, p 51 transparencia y participación ciudadana ${ }^{7}$. De igual manera cabe mencionar que en Honduras la Administración Pública se divide en: Centralizada y Descentralizada. Según los artículos 9, 10 y 11 de este mismo cuerpo legal antes mencionado, se plantea que la Administración Pública Centralizada está constituida por los órganos del Poder Ejecutivo, los cuales son: La Presidencia de la República, El Consejo de Ministros y Las Secretarías de Estado. Aunado a lo anterior de igual forma se establece que el presidente de la Republica tiene a su cargo la suprema dirección y coordinación de la Administración Pública Centralizada y Descentralizada, quedando evidenciado que cuando se habla de las funciones del Poder Ejecutivo y del Presidente de la República, estas se subsumen dentro del ámbito de aplicación del Derecho Administrativo. ${ }^{8}$

De igual manera se considera imprescindible hacer hincapié del papel que juega la Administración Pública a través del Presidente en la creación de leyes dentro del territorio nacional, ya que acorde a la Constitución de la República en sus artículos 213, 215 y 216 el Presidente tiene iniciativa de ley por medio de los Secretarios y de igual manera tiene la potestad de sancionar todas aquellas leyes que son aprobadas en el Congreso Nacional y lo que se considera más importante para el juego democrático y el Estado de Derecho es la potestad que tiene el Presidente de la República de vetar aquellos proyectos de ley que considere inconstitucionales y estos no podrán ser sometidos a un nueva deliberación sin antes escuchar la opinión de la Corte Suprema de Justicia. ${ }^{9}$

7 PODER LEGISLATIVO, Ley General de la Administración Pública, Tegucigalpa M.D.C, Diario Oficial la Gaceta, 29 de noviembre de 1986, p 7.

8 PODER LEGISLATIVO, Ley General de la Administración Pública, Tegucigalpa M.D.C, Diario Oficial la Gaceta, 29 de noviembre de 1986, p9. 


\subsection{Los Titulares de la Administración Pública Hondureña y su accionar en contra del Estado de Derecho}

La transición e implementación del actual Estado de Derecho, el cual es la institucionalización jurídica de la democracia ${ }^{10}$, se presenta en América Latina como resultado de la lucha contra los gobiernos autoritaritas, esta es una conquista social relativamente reciente ya que dichos acontecimientos se fraguaron entre la década de los $80 \mathrm{~s}$ y $90 \mathrm{~s}^{11}$. De igual manera no es algo nuevo de que en el actual Estado de Derecho implementado en América Latina existe una gran concentración de poder en el Ejecutivo y en la figura del Presidente, ya que nuestro sistema está inspirado en el régimen de gobierno presidencialista de los Estados Unidos, circunstancia que ha originado prácticas autoritarias desde los mismos poderes democráticos afectando directamente la dinámica de la democracia por medio de la afectación a los estándares que debe cumplir un Estado de Derecho. $^{12}$

Es por lo anteriormente expuesto que a continuación se evidenciará como los Titulares de la Administración Pública Hondureña ha contravenido las bases del Estado de Derecho.

9 PODER LEGISLATIVO, Constitución de la Republica de Honduras, Tegucigalpa M.D.C, Diario Oficial la Gaceta, 20 de enero de 1982, p 102.

10 DIAZ Elías, Estado de derecho y sociedad democrática, Cuadernos para el Diálogo, Madrid, 1966, p 203.

11 MUNK Gerardo, "Revista de Ciencia Política Santiago", Los orígenes y la durabilidad de la democracia en América Latina: Avances y retos de una agenda de investigación, 2010, Disponible en Línea: https://scielo.conicyt.cl/scielo. php?script=sci_arttext\&pid=S0718-090X2010000300001, Acceso en: 16 de octubre del 2020.

12 ESPADA Darío German, "Las Practicas Defectuosas en la Región”, Predominio del Poder Ejecutivo en América Latina, 2 se septiembre del 2013.

\subsubsection{La Administración Pública de Honduras ante la División de Poderes}

Uno de los pilares fundamentales del Estado de Derecho es la división del Poder Estatal, dicha división se lleva a cabo por medio del Poder Ejecutivo, Legislativo y Judicial, los cuales deben de ser complementarios $\mathrm{e}$ independientes $\mathrm{y}$ sin relaciones de subordinación ${ }^{13}$, cumpliendo estos la función de pesos y contrapesos.

En Honduras en el año de 2011 se creó la Ley Especial del Consejo de Defensa y Seguridad mediante la cual se creó el Consejo Nacional De Defensa y Seguridad. Acorde al artículo 1 de dicha normativa legal, este consejo debe de estar integrado de la siguiente manera: El Presidente de la Republica en representación del Poder Ejecutivo, El Presidente del Congreso Nacional en representación del Poder Legislativo, EL presidente de la Corte Suprema De Justicia en representación del Poder Judicial, El Fiscal General, El Secretario de Estado en el Despacho de Seguridad y El Secretario de Estado en el Despacho de Defensa..$^{14}$

Es importante mencionar que el presidente de la Republica es el encargado de presidir el Consejo Nacional de Defensa y Seguridad, de esta manera se puede decir con certeza que este consejo es completamente inconstitucional por atentar directamente

13 SALAMANCA Andrés Bordalí, "Revista de Derecho Valparaiso", La doctrina de la separación de poderes y el poder judicial chileno, 2018, Disponible en Línea: https://scielo.conicyt.cl/scielo.php?script=sci_arttext\&pid $=$ S0718-68512008000100004, Acceso en 17 de octubre del 2020.

14 PODER LEGISLATIVO, Ley Especial del Consejo de Defensa y Seguridad, Tegucigalpa M.D.C, Diario Oficial la Gaceta, 12 de diciembre del 2011, p 1, 2 y 3. 
contra el artículo 4 de la Constitución de la República, el cual dice literalmente lo siguiente: La forma de gobierno es republicana, democrática y representativa. Se ejerce por tres poderes; Legislativo, Ejecutivo y Judicial, complementarios e independientes y sin relaciones de subordinación. ${ }^{15}$

Según el nuevo paradigma creado luego de la segunda guerra mundial respecto a la División de Poderes se le asigna una doble finalidad al principio de la división de poderes y al derecho administrativo como rama autónoma del derecho público. Por un lado, deben satisfacer la ordenación, disciplina $\mathrm{y}$ modulación del poder y, por otro lado, deben ser flexibles, dinámicos y funcionales de modo tal que se tornen eficaces y eficientes en su conjugación en el marco del accionar estatal (utilizando de forma ineludible procedimientos y procesos estandarizados universalmente). De este modo se presume, iuris tantum, que se asegura la efectividad de los derechos fundamentales. ${ }^{16}$

Seguido a lo anterior se puede concluir diciendo que la Administración Pública a través Del Presidente de la Republica ha desempeñado un papel fundamental en la violación realizada por el Estado de Honduras al principio de División de Poderes, el cual es indispensable para todo Estado de Derecho. Por un lado, El Presidente de la Republica ha incumplido el deber constitucional propio

15 PODER LEGISLATIVO, Constitución de la República de Honduras, Tegucigalpa M.D.C, Diario Oficial la Gaceta, 20 de enero de 1982, p 5.

16 CORVALAN Juan Gustavo, "Revista de Investigações Constitucionais", Los ejes centrales de la división de poderes en el Estado Constitucional de Derecho, 15 de abril del 2019, Disponible en Línea: https://www.scielo.br/scielo.php?pid=S235956392015000100225\&script=sci_arttext\#fn118, Acceso en: 18 de octubre. del juego democrático de pesos y contrapesos de vetar todo proyecto de ley que considere que sea inconstitucional y en este caso la Administración Pública por medio del Presidente no ha vetado la Ley Especial del Consejo de Defensa y Seguridad y por otro lado se ha prestado a formar parte y presidir el Consejo Nacional de Defensa y Seguridad en el cual se subordinan al Poder Ejecutivo los titulares del Poder Judicial y Legislativo. La intención es clara, se busca la concentración de poder en el Ejecutivo y de esta manera favorecer a la corrupción y generar un clima de impunidad para los corruptos. Es debido a esto que el Estado de Honduras ha sido declarado según el Índice Global de Impunidad como el país más impune de América y el segundo a nivel mundial. ${ }^{17}$

\subsubsection{El Derecho Humano de Acceso a la Información Pública}

El Estado de Honduras ha ratificado diferentes instrumentos internacionales en los cuales se establece la obligación activa de garantizar el Derecho Humano de Acceso a la Información Pública a sus ciudadanos, en esta ocasión se enfatizará en el Sistema Interamericano de Derechos Humanos. La Corte Interamericana de Derechos Humanos en el caso, Claudio Reyes y otros vs. Chile declaro el Acceso a la Información Pública como un Derecho Humano ${ }^{18}$, aunado

17 EL LIBERTADO, ;Alarmante! / Honduras, el más impune de América y Segundo del Mundo, 25 de agosto del 2020, Disponible en Linea: http://www.web.ellibertador.hn/index.php/ noticias/nacionales/2203-alarmante-honduras-el-mas-impunede-america-y-segundo-del-mundo, Acceso en 18 de octubre del 2020.

18 RODRIGUEZ ACEITUNO Rene Fernando, "Revista de Derecho. Vol. 38, No. 1", El Derecho de Acceso a la Información Pública como un Derecho Fundamental, 15 de mayo del 2017.

Revista de Derecho. Vol. 12, No. 1, Año 2021 $\mid-55$ 
a esto es importante mencionar que el Estado de Honduras ratifico la Convención Interamericana de Derechos Humanos en el año de 1977 y posteriormente reconoció la Competencia de la Corte Interamericana de Derechos Humanos en el año de 1981, por lo tanto toda los derechos reconocidos en las sentencias de la Corte Interamericana de Derechos Humanos le son directamente vinculantes y debe de tomar todas las medidas requeridas para el obligatorio cumplimiento de los derechos que estas reconocen.

En Honduras en el año de 2006 se creó la Ley de Transparencia y Acceso a la Información Pública a través de la cual se pretendía el desarrollo y ejecución de una política de transparencia, así como hacer posible a toda persona el ejercicio de su derecho al Acceso a la Información Pública y de esta manera lograr el fortalecimiento del Estado de Derecho y la Consolidación de la Democracia mediante la participación ciudadana. ${ }^{19}$

El avance que se había logrado respecto al derecho humano de Acceso a la Información Pública con la normativa legal antes mencionada quedo reducido a nada con la entrada en Vigencia de la Ley para la Clasificación De Documentos Públicos Relacionados con la Defensa y Seguridad Nacional en el año 2014, a través de la cual se estableció una nueva gradualidad respecto a la duración de la clasificación de documentos públicos en materia de Seguridad y Defensa, representando esta nueva gradualidad un aumento estratosférico en relación a lo que establecía la Ley de Transparencia y Acceso

19 PODER LEGISLATIVO, Ley de Transparencia y acceso a la Información Pública, Tegucigalpa M.D.C, Diario Oficial la Gaceta, 30 de diciembre del 2006, p 12. a la Información Pública en la cual el termino máximo de duración del Secreto de Estado era de 10 años ${ }^{20}$

Con la Ley para la Clasificación de Documentos Públicos relacionados con la Defensa y la Seguridad Nacional se plantea la siguiente clasificación y duración de los secretos de estado en Materia de Seguridad y Defensa:

- Documentos Reservados: la desclasificación se llevará a cabo en 5 años.

- Documentos Confidenciales: la desclasificación se llevará a cabo en 10 años.

- Documentos Secretos: la desclasificación se llevará a cabo en 15 años.

- Documentos Ultra Secretos: la desclasificación se llevará a cabo en 25 años.

En este mismo cuerpo legal se establece que la clasificación y desclasificación de documentos públicos bajo Secreto de Estado en materia de Seguridad y Defensa le corresponderá exclusivamente al Consejo Nacional de Seguridad y Defensa CNDS, que como lo establecimos anteriormente es completamente inconstitucional, y deja al arbitrio de este mismo consejo el extender el plazo de la duración del Secreto de Estado bajo el cual se encuentra un documento público, de igual manera se plantea que la única forma de obtener información respecto a un documento clasificado es mediante una solicitud realizada por el Congreso Nacional de la Republica dirigida al Consejo Nacional

20 PODER LEGISLATIVO, Ley de Transparencia y acceso a la Información Pública, Tegucigalpa M.D.C, Diario Oficial la Gaceta, 30 de diciembre del 2006, p 13. 
de Defensa y Seguridad y solo de esta manera dicho consejo podrá acceder a desclasificar el documento si así lo quisiere. ${ }^{21}$

Cabe mencionar que el gran interés de proteger bajo Secreto de Estado todos los documentos públicos relacionados con la defensa y seguridad es debido a que a dicha materia se le asigna la mayor cantidad de fondos públicos, creando de esta manera un ambiente propicio para la corrupción en la compras y contrataciones públicas ${ }^{22}$.

Según el, Dr. Elías Diaz, los Derechos Humanos constituyen la razón de ser de Estado de Derecho ${ }^{23}$, de igual manera como se ha establecido desde un inicio, el respeto y garantía a los Derechos Humanos representa una de las bases del Estado de Derecho.

Los Titulares de la Administración Pública Hondureña ha incumplido su obligación imperativa de contribuir al fortalecimiento del Estado de Derecho, ya que dándole seguimiento al actuar administrativo se puede decir que estos han hecho todo lo contrario, dejando en evidencia que los Titulares de la Administración Pública Hondureña han formado parte fundamental en la limitación e irrespeto hacia el Derecho Humano de Acceso a la Información Pública por haber formado parte de la creación de la Ley para la Clasificación de Documentos

21 PODER LEGISLATIVO, Ley para la Clasificación De Documentos Publico Relacionados con la Defensa y Seguridad Nacional, Tegucigalpa M.D.C, Diario Oficial la Gaceta, 24 de enero del 2014, p 2,3 y 4.

22 CRITERIO.HN, ¿Cuál es el costo de la seguridad y la defensa en Honduras?, 23 DE ENRO DEL 2019, Disponible en línea: https://criterio.hn/cual-es-el-costo-de-la-seguridad-y-ladefensa-en-honduras/, Acceso en 17 de octubre del 2020.

23 DIAZ Elías, Estado de derecho y sociedad democrática, Cuadernos para el Diálogo, Madrid, 1966, p 203.
Públicos relacionados con la Defensa y la Seguridad Nacional, puesto que como lo explicamos anteriormente según el mandato constitucional y el juego democrático le corresponde al Poder Ejecutivo a través del Presidente la sanción de los proyectos de ley emitidos por el Congreso Nacional y vetarlos cuando estos sean inconstitucionales, y en este caso la Administración Pública a través del Presidente no ha tenido ni la mínima intención en vetar dicha ley, la cual es evidentemente inconstitucional por limitar el Derecho Humano de Acceso a la Información Pública y dejar al arbitrio de un Consejo la duración de los Secretos de Estado respecto a los Documentos Públicos.

Lo anteriormente expuesto son prácticas que van en contra de la Transparencia en la Admiración Publica y han llevado a ubicar a Honduras según el informe de Trasparencia Internacional en el cuarto lugar de los países más corruptos de América Latina. ${ }^{24}$

\subsubsection{Los Titulares de la Administración Pública Hondureña y el Imperio de la Ley}

EL Imperio de la Ley consiste en la sumisión de las autoridades al derecho y en especial sumisión de la administración a la ley. Cabe mencionar que no es el imperio de cualquier ley sino de aquellas que son producto de la libre participación popular. E1 respeto por parte de la Administración Pública al Imperio de la Ley es una Característica y elemento fundamental que debe de existir en todo Estado de Derecho ${ }^{25}$. De igual manera se 24 HONDUDIARIO, honduras "más corrupto" durante 2019 según transparencia internacional, 23 de enero del 2020 , Disponible en Línea: https://hondudiario.com/2020/01/23/ honduras-mas-corrupto-durante-2019-segun-transparenciainternacional/, Acceso en: 17 de Octubre del 2020.

25 MARSHALL BARBERÁN Pablo, "Revista de derecho 
entiende que el imperio de la ley es el imperio de Constitución por ser esta la norma suprema de todo Estado de Derecho.

En Honduras la reelección presidencial está completamente prohibida ya que para el legislador de la Constitución de la Republica de Honduras de 1982 era la mejor medida en la lucha para erradicar los gobiernos totalitaristas y autoritarios que habían existido en las épocas anteriores a nuestra Carta Magna. Dicha prohibición se establece a través de los artículos constitucionales 4,42 , 239 y el $274 .^{26}$

En la actualidad el presidente, Juan Orlando Hernández, está cumpliendo su tercer año de gobierno correspondiente a su segundo periodo presidencial, violentando de esta manera los preceptos constitucionales antes mencionados en los cuales se prohíbe la reelección presidencial.

Cabe mencionar que la Reelección se habilito ilegalmente en Honduras por medio de la interposición de un recurso de Inconstitucionalidad interpuesto por un grupo de diputados y un expresidente ante la Sala de lo Constitucional de la Corte Suprema de Justicia. La Sala de lo Constitucional resolvió declarando inconstitucional la Constitución misma lo cual es ilusorio y descabellado ya que la Sala de lo Constitucional es manifiestamente incompetente para tramitar el recurso de inconstitucionalidad contra una

(Coquimbo)", El Estado de Derecho como Principio y su Consagración en la Constitución Política, 2010, Disponible en línea: https://scielo.conicyt.cl/scielo.php?script=sci_arttext\&p $\mathrm{id}=$ S0718-97532010000200008, Acceso en 17 de octubre del 2020.

26 PODER LEGISLATIVO, Constitución de la República de Honduras, Tegucigalpa M.D.C, Diario Oficial la Gaceta, 20 de enero de 1982, p 4, 60, 109 y 121. norma constitucional originaria actuando en una clara usurpación de funciones del poder constituyente $^{27}$, por ende, los efectos legales de la prohibición de la Reelección Presidencial siguen vigentes. Este actuar de la Corte Suprema de Justica no es algo de sorprender, ya que como lo planteamos anteriormente el Poder Judicial en Honduras está a merced del Poder Ejecutivo mediante una relación de subordinación existente gracias al Consejo Nacional de Defensa y Seguridad.

La Reelección Presidencial del señor, Juan Orlando Hernández, es la piedra angular para decir que en Honduras no existe un Estado de Derecho, causando este actuar del Presidente un efecto domino en los funcionarios y empleados públicos y los administrados en general, a razón que incentiva el irrespeto de la Ley, viéndose afectado el buen funcionamiento de la Administración Pública por los Titulares la misma Administración Pública, haciendo más difícil la transparencia y la rendición de cuentas en el actuar Administrativo y fomentando la corrupción en todas la escalas.

\subsubsection{La respuesta de la Administración Pública hondureña al Covid-19 ante la ausencia del Estado de Derecho}

EL manejo de la Pandemia por los Titulares de la Administración Pública Hondureña ha estado caracterizado por las constantes denuncias de violaciones de Derechos Humanos y por la falta de 27 ELEUTRA HONDURAS, REDACCION, Análisis de la sentencia de la Sala de lo Constitucional de Honduras que elimina artículos constitucionales pétreos y establece la reelección presidencial indefinida, 1 de mayo del 2015, Disponible en Linea: http://www.eleutera.org/analisis-del-fallo-que-eliminaarticulos-constitucionales-petreos-y-establece-la-reeleccionpresidencial-indefinida/, Acceso en 18 de octubre del 2020. 
trasparencia por parte del gobierno respecto al uso de los recursos para hacer frente a la pandemia $^{28}$. Desde los inicios del mes de marzo del año 2020 se aprobaron miles de millones de lempiras para hacer frente al virus, siendo Honduras el país con mayor presupuesto de Centroamérica para dicho fin. Dinero que no se ha visto reflejado en el Sistema de Salud Hondureño puesto que los hospitales siguen con las mismas carencias de antes y de igual manera no ha habido nuevas construcciones. Ante el descontento y repudio de la población hacia los gobernantes del país surgió la campaña “¿Dónde Está el Dinero?” a través de la cual los ciudadanos pintaban las principales calles de Honduras con dicha frase, así como de igual manera inundan las redes sociales con frase ¿DÓNDE ESTÁ EL DINERO?

Para ilustrar las irregularidades en las compras públicas durante la pandemia, haremos mención de la compra de siete hospitales móviles de aislamiento, dicha compra se llevó a cabo por la cantidad de 46.9 millones de dólares $(1,158.4)$ millones de lempiras en el mes de marzo, con una sobrevaloración del $69 \%$, según un informe divulgado el 20 de julio del 2020cpor el Consejo Nacional Anticorrupción (CNA), ya que el costo real es de 14 millones de dólares y no de 46.9 millones de dólares. Cabe mencionar de los sietes hospitales móviles hasta el mes de Julio del 2020 solo habían llegado dos de ellos al territorio Nacional, de igual manera según una inspección del Ministerio Público, en los contenedores venían accesorios médicos usados, deteriorados y que vencieron

28 TELESUR HD, ¿Cómo se ha vivido en Honduras la pandemia por Covid-19?, 15 de septiembre del 2020, Disponible en Línea: https://www.telesurtv.net/news/honduras-situacionddhh-corrupcion-pandemia-20200915-0006.html, Acceso en 18 de octubre del 2020 . desde el 2016 ${ }^{29}$. Es importante señalar que la Administración Pública trata de ocultar la mayor cantidad de información respecto al destino que le da al erario público y por otro lado los Hondureños mueren ya sea producto del Covid-19 o por la misma hambre debido a caída de la economía en contraste con la falta de iniciativas para dicho sector, siendo este el actuar característico de un país donde no existe Estado de Derecho en donde impera el irrespeto a los Derechos Humanos y Reina la Corrupción.

\section{CONCLUSIONES}

1. ElEstadodeDerechoesla Institucionalización Jurídica de la Democracia a través de la implementación de sus bases: el Imperio de la Ley, La División de Poderes, El control y fiscalización de los Poderes Públicos y el Respeto y Garantía de los Derechos Humanos. Solo de esta manera una nación podrá asegurarles a los ciudadanos dentro de su jurisdicción el goce de la justicia, la libertad, la cultura y el bienestar económico y social.

2. La Administración Pública está en la posición garante $y$ tiene como objeto fortalecer el Estado de Derecho desde el lugar que ocupa en el juego democrático de pesos y contrapesos así como de igual manera con la implementación de políticas públicas a favor de esté.

29 CRITERIO.HN, Honduras: La corrupción y la miseria del sistema de salud provocan muerte y desesperanza, 10 de agosto del 2020, Disponible en Línea: https://criterio.hn/honduras-lacorrupcion-y-la-miseria-del-sistema-de-salud-provocan-muerte-ydesesperanza/, Acceso en: 18 de octubre del 2020.

Revista de Derecho. Vol. 12, No. 1, Año 2021 $\mid-59$ 
3. Los Titulares de la Administración Publica del Estado de Honduras han quebrantado el Estado de Derecho al haber formado parte de la creación de leyes Inconstitucionales y violatorias de Derechos Humanos, de acorde al papel que le asigna la Constitución de la Republica a la Administración Pública por medio del presidente en el juego democrático de pesos y contrapesos. De igual manera la Administración Pública a través del Presidente ha quebrantado el Imperio de la ley, ya que este ha violentado la Constitución de la Republica al legalizar la reelección de manera ilegal e inconstitucional suprimiendo por completo El Estado de Derecho.

4. El Estado de Derecho juega un papel imprescindible en el respeto a los Derechos Humanos, la Transparencia, la Corrupción y la Impunidad. El efecto de la ausencia del Estado de Derecho en Honduras es notable, ubicando al país en el cuarto lugar dentro de los países más corruptos de América Latina y el numero uno respecto a índices de Impunidad en la misma región.

5. El actuar de los Titulares de la Administración Pública ante la ausencia del Estado de Derecho durante el Estado Emergencia generado por el Covid-19 ha sido un caos, donde impera la corrupción y la impunidad, exponiendo todo lo anterior para que el caso de Honduras sirva de ejemplo e incentive a los demás países de América Latina para que fortalezcan el Estado de Derecho.

\section{REFERENCIA BIBLIOGRÁFICAS}

- INTERNACIONAL, "Plataforma Digital de Derecho, Ciencias Sociales y Humanidades”, Historia del Estado de Derecho, 21 de febrero del 2020, Disponible en línea: https://

60-|Revista de Derecho. Vol. 42, No. 1, Año 2021 leyderecho.org/historia-del-estado-dederecho/, Acceso en 16 do octubre del 2020.

- Oas.org. 2020. 15 octubre 2020, Disponible

en Línea: https://www.oas.org/dil/esp/ constitucion chile.pdf. Acceso en: 16 de octubre del 2020.

- Biblioteca del Congreso Nacional de Chile, Guia de Formación Cívica Estado, Disponible en Línea: https:// www.bcn.cl/formacioncivica/detalle guia?h=10221.3/45680, Acceso en 16 de octubre del 2020.

- VILHENA VIEIRA Oscar, "SUR REVISTA INTERNACIONAL DE DERECHOS HUMANOS “, La Desigualdad y la Subversión del Estado de Derecho, 2007, p 3.

- PODER LEGISLATIVO, Constitución de la República de Honduras, Tegucigalpa M.D.C, Diario Oficial la Gaceta, 20 de enero de 1982, p51.

- PODER LEGISLATIVO, Ley General de la Administración Pública, Tegucigalpa M.D.C, Diario Oficial la Gaceta, 29 de noviembre de 1986, p7.

- ESPADA Darío German, "Las Practicas Defectuosas en la Región”, Predominio del Poder Ejecutivo en América Latina, 2 se septiembre del 2013.

- MUNK Gerardo, "Revista de Ciencia Política Santiago", Los orígenes y la durabilidad de la democracia en América Latina: Avances y retos de una agenda de investigación, 2010, Disponible en Línea: https://scielo.conicyt.

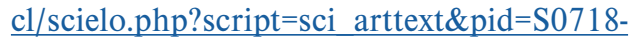
090X2010000300001, Acceso en: 16 de octubre del 2020.

- RODRIGUEZ ACEITUNO Rene Fernando, "Revista de Derecho. Vol. 38, No. 1", El 
Derecho de Acceso a la Información Pública como un Derecho Fundamental, 15 de mayo del 2017.

- PODER LEGISLATIVO, Ley de Transparencia y acceso a la Información Pública, Tegucigalpa M.D.C, Diario Oficial la Gaceta, 30 de diciembre del 2006, p 12.

- PODER LEGISLATIVO, Ley para la Clasificación De Documentos Publico Relacionados con la Defensa y Seguridad Nacional, Tegucigalpa M.D.C, Diario Oficial la Gaceta, 24 de enero del 2014, p 2,3 y 4.

- SALAMANCA Andrés Bordalí, "Revista de Derecho Valparaiso", La doctrina de la separación de poderes y el poder judicial chileno, 2018, Disponible en Línea:

- MARSHALL BARBERÁN Pablo, "Revista de derecho (Coquimbo)", El Estado de Derecho como Principio y su Consagración en la Constitución Política, 2010, Disponible en línea: https://scielo. conicyt.cl/scielo.php?script=sci_arttext\&pid $=$ S0718-97532010000200008, Acceso en 17 de octubre del 2020.

- CRITERIO.HAN, ¿Cuál es el costo de la seguridad y la defensa en Honduras?, 23 DE ENRO DEL 2019, Disponible en línea: https://criterio.hn/cual-es-el-costo-de-laseguridad-y-la-defensa-en-honduras/, Acceso en 17 de octubre del 2020.

- HONDUDIARIO, honduras "más corrupto" durante 2019segúntransparenciainternacional, 23 de enero del 2020, Disponible en Línea: https://hondudiario.com/2020/01/23/ honduras-mas-corrupto-durante-2019-seguntransparencia-internacional/, Acceso en: 17 de octubre del 2020.
- CORVALAN Juan Gustavo, "Revista de Investigações Constitucionais”, Los ejes centrales de la división de poderes en el Estado Constitucional de Derecho, 15 de abril del 2019, Disponible en Linea: https:// www.scielo.br/scielo.php? pid $=\mathrm{S} 2359$ $56392015000100225 \& \mathrm{script}=\mathrm{sci}$ arttext\#fn118, Acceso en: 18 de octubre.

- EL LIBERTADO, ;Alarmante! / Honduras, el más impune de América y Segundo del Mundo, 25 de agosto del 2020, Disponible en Línea: http://www.web.ellibertador.hn/index. $\mathrm{php} /$ noticias/nacionales/2203-alarmantehonduras-el-mas-impune-de-america-ysegundo-del-mundo, Acceso en 18 de octubre del 2020.

- ElEUTRA HONDURAS, REDACCION, Análisis de la sentencia de la Sala de lo Constitucional de Honduras que elimina artículos constitucionales pétreos y establece la reelección presidencial indefinida, 1 de mayo del 2015, Disponible en Línea: http:// www.eleutera.org/analisis-del-fallo-queelimina-articulos-constitucionales-petreos-y establece-la-reeleccion-presidencialindefinida/, Acceso en 18 de octubre del 2020.

- TELESUR HD, ¿Cómo se ha vivido en Honduras la pandemia por Covid-19?, 15 de septiembre del 2020, Disponible en Línea: https://www.telesurtv.net/news/ honduras-situacion-ddhh-corrupcionpandemia-20200915-0006.html, Acceso en 18 de octubre del 2020. 